\title{
Assessing the relationship between student learning characteristics and academic performance in chemical pathology in an undergraduate medical curriculum
}

\author{
A. A. K. Wamono', A.O. Adefuye ${ }^{2} \&$ J. Busari ${ }^{3}$
}

\begin{abstract}
Background: Teaching and learning chemical pathology requires that medical trainees interpret biochemical test results correctly (against the background of clinical information) to solve clinical problems, while being aware of factors that could affect results. To meet these competencies, students must possess certain learning characteristics. This study explored the relationship between student learning characteristics and academic performance in chemical pathology. It is expected that a better understanding of the relationship between students' learning characteristics and academic performance will help formulate strategies to enhance teaching and learning of this subject.
\end{abstract}

Methods: This study was designed as an exploratory survey. Self-administered, validated questionnaires were used to obtain data on learning mode, learning style and learning approach from 250 fourth-year undergraduate medical students at a medical university in South Africa. One-way ANOVA and Pearson correlations were used to analyse the relationship between each learning characteristic and academic performance. Spearman's rho was used to study the relationships between the three learning characteristics.

Results: A response rate of $72 \%$ was obtained. The largest number of participants (35\%; $\mathrm{n}=63)$ were visual learners, pragmatists $(25 \% ; \mathrm{n}=45)$ and learned using a superficial approach $(44 \% ; n=79)$. Multimodal learning mode, balanced learning style and deep

\footnotetext{
National Health Laboratory Services, Division of Chemical Pathology, Faculty of Medicine and Health Sciences, Stellenbosch University, Cape Town, South Africa

2 Division of Health Sciences Education, Faculty of Health Sciences, University of the Free State, South Africa

3 Faculty of Health, Medicine and Life Sciences, Maastricht University, Maastricht, The Netherlands
}

\section{Correspondence}

Associate Professor Anthonio Oladele Adefuye

Division Health Sciences Education, Faculty of Health Sciences

University of the Free State

PO Box 339

205 Nelson Mandela Drive

Park West, Bloemfontein 9300

South Africa

Tel: +27514017510

Email: AdefuyeAO@ufs.ac.za 
learning approach were found to correlate significantly with better academic performance in chemical pathology $(r=0.262,0.307$ and 0.467 , respectively; $p \leq 0.0001)$.

Conclusions: Our findings reveal that multimodal learners with a balanced learning style who have a deep approach to learning performed well in chemical pathology. This concurs with findings by studies that report a positive association between these learning characteristics and academic performance in other subjects in medicine. We propose that to achieve effective student learning, chemical pathology educators explore alternative teaching and learning activities to move students towards these positive learning characteristics.

Keywords: learning characteristics; students; chemical pathology; academic performance

\section{Introduction}

Chemical pathology is a subject that integrates medical biochemistry, physiology, pathology and clinical medicine into a single domain of knowledge. In undergraduate medical education, knowledge of chemical pathology is essential for helping medical students understand normal bodily functions (physiology), abnormal clinical states (pathology) and medical biochemistry. Aptly applied, these three knowledge domains enable students to solve clinical problems and correctly interpret biochemical test results against the background of a broad knowledge of factors affecting health outcomes and to manage the rational and practical use of biochemical investigations (Lau et al., 2018). Over the years, studies have identified chemical pathology knowledge deficiencies in medical students, interns and junior doctors. Khromova and Gray (2008) report that junior doctors lacked confidence in interpreting laboratory results and were unsure of the effects of common clinical problems, such as haemolysis of a sample, when interpreting results. In a similar study, Stanfliet et al. (2009) report that medical interns at two hospitals in Cape Town, South Africa, were not confident about interpreting laboratory tests and agreed that they would benefit from extra tuition in at least one area of chemical pathology. In a survey to investigate medical students' knowledge of and competence in chemical pathology, Lau et al. (2018) report knowledge deficiencies in medical students in relation to requesting and interpreting biochemical tests. While inadequate knowledge of chemical pathology in medical students has been attributed to unsatisfactory teaching in the undergraduate medical curriculum (Lau et al., 2018), little is known about the relationship between student learning characteristics (learning mode, learning style and learning approach) and academic performance in the subject.

Studies have shown that undergraduate medical students need to develop multimodal learning and deep learning approaches if they are to learn effectively (Bokhari \& Zafar, 2019). Lujan and DiCarlo (2006) report that students with multiple learning modes are more likely to self-direct to access various resources and find it easier to understand the material. Similarly, Honey and Mumford (1982) argue, on the basis of Kolb's experiential learning cycle (Honey \& Mumford, 1982; A. Kolb, 2013; D. Kolb, 2014; D. Kolb \& 
Fry, 1974), that individuals with a balanced learning style (i.e., between theorist, activist, reflector and pragmatist learning approaches) are much more likely to complete the learning cycle, achieve deeper understanding and conceptualisation of knowledge, and transform this knowledge into skill. Finally, Biggs (2012) found that students with strong motivation to learn deeply (i.e., learning to understand) and apply clinically (i.e., a desire to apply the understanding in practical solutions) are more successful in attaining their learning outcomes.

This study explored the relationship between student learning characteristics and academic performance in the context of the subject, chemical pathology, which, to the best of our knowledge, has not been investigated previously. We used three already validated questionnaires to obtain data on students' learning modes, approaches and styles, and evaluated the trends of these learning characteristics on academic performance in the first-semester test in chemical pathology. We assumed that a better understanding of the relationship between students' learning characteristics and academic performance would help us formulate strategies to enhance teaching and learning of this subject.

\section{Study context}

This study was conducted at the Sefako Makgatho Health Sciences University (SMU), situated in Pretoria, Gauteng Province, South Africa. At SMU, chemical pathology is a standalone module presented in the fourth year of the undergraduate medical curriculum. Teaching is via didactic lectures and monthly tutorials in a small-group setting, using simulated case scenarios. The module's learning outcome is that students should understand the mechanism of diseases and disease progression and how these lead to changes in biochemical parameters. In addition, students must be able to apply this knowledge and select appropriate laboratory investigations for patient management. Assessment in the module is formative. Students undertake four tests comprising multiple-choice questions to test theory and clinical case questions. To this end, students must think critically and conceptualise disease processes and then apply the constructed knowledge to solve clinical problems in the case scenarios during the assessments. Students at this university are from diverse educational backgrounds and have access to varied resources and opportunities to develop learning methods. Each year, several students are found to struggle in the program and fail their first-semester tests in chemical pathology. As a result, the need emerged to understand students' learning characteristics and how they affect their academic performance in chemical pathology. Furthermore, the authors wished to investigate and develop strategies that would lead to the attainment of the desired learning outcomes.

\section{Methods}

The study design was an exploratory survey that used self-administered, validated questionnaires. Ethical approval was obtained from the Health Science Research Ethics Committee, University of the Free State (UFS-HSD2019/2028/2403). The SMU 
research ethics committee granted site approval. Recruitment of participants was done with the assistance of the program coordinator of chemical pathology, who provided the names and email addresses of all the fourth-year MBChB students. All of them had undertaken the first-semester test in chemical pathology in 2020. An email with an invitation to participate in the study was sent to all the students. Attached to the email were an information letter and a consent form that guaranteed anonymity. Students who consented signed the consent form and emailed it back to one of the researchers. All participants were free to leave the study at any time without any consequences. All collated data were saved electronically in an Excel spreadsheet that is password protected. The study was conducted from January to July 2020.

\section{Study population}

The study population comprised 250 fourth-year MBCHB students who had undertaken the first-semester test in chemical pathology during the 2020 academic year. A comprehensive sampling technique was used, inviting all students in the class to participate in the study.

\section{Data collection}

After consenting, two online links and one electronic copy of the three already validated questionnaires - to evaluate learning modes, learning styles and learning approaches, respectively_-were sent to each participant via email. A second, follow-up email explaining the process and the questionnaire's details was sent to all participants 1 week later. Furthermore, one-on-one online Zoom meetings were held with participants who needed further clarification. Each questionnaire was self-administered, and scores were interpreted according to the guidelines given by each tool. Students' marks in the firstsemester test in chemical pathology were provided by the department, as consented to by students, and used to determine different academic performance levels. The firstsemester test covered the curriculum's early scope, and the test format was online multiple-choice questions.

\section{Learning modes inventory}

The online version 7.8 of the VARK (visual, auditory, read and write, kinaesthetic) questionnaire, developed by Neil Fleming in 1987 and trademarked in 2012 by Fleming and Mills (VARK Learning Limited), was used with permission (VARK Learning Limited, 2020). The questionnaire consists of 16 multiple-choice questions that determine students' preferred mode(s) of learning. Each question places the respondents in a "learning" situation, and participants are informed that there are no right or wrong answers. This means their answers should represent what they would do in the context of each question and not what they believe is expected of them. All choices correspond to the four identified learning modes: visual, aural, read and write, and kinaesthetic. Participants could select one or more choices for each question, skip a question or choose two or more options, if appropriate. A multimodal learning mode $(\mathrm{M})$ is automatically 
reported when a participant has an equal distribution in two or more modes. Individual reports were downloaded and emailed to one of the researchers (AAKW). Reliability estimate scores of the VARK subscales, as determined by Leite et al. (2010), were $0.85,0.82,0.84$ and 0.77 , respectively, for the visual, aural, read/write and kinaesthetic subscales, respectively.

\section{The learning styles inventory}

The online version of Honey and Mumford's Learning Styles Questionnaire was used to obtain data on participants' learning personalities (https://www.mint-hr.com/ mumford.html). The 80 questions of this tool were designed to probe individuals' general behavioural tendencies during experiences usually encountered during learning or working. This tool is underpinned by the concept of Kolb's experiential learning cycle, which proposes that learning is complete if the person goes through four sequential stages, namely, abstract conceptualisation, active experimenting, concrete experience and reflective observation (A. Kolb, 2013; D. Kolb \& Fry, 1974). Honey and Mumford (1982) propose four types of learners: theorist, pragmatist, activist and reflector, relating to these stages of Kolb's experiential learning cycle. Factorial validity and internal reliability of Honey and Mumford's Learning Styles Questionnaire were more acceptable than that of Kolb’s Learning Style Inventory (Cockerton et al., 2002).

Respondents indicate the statements they agree with in the online questionnaire. The questionnaire's scoring system is automated, and the percentage scores for each of the four learning styles are recorded. The learning style with the highest score is defined as a respondent's preferred learning style. When the scores of all four styles are distributed equally, a participant is said to have a balanced learning style (Urban, 2004), which, when the scores are plotted on a four-axis scale, is depicted by an evenly distributed kite report (Figure 1) (A. Kolb, 2013).

\section{Figure 1}

A Kite-Shaped Learning Style Report for an Individual, Showing Pragmatist and Theorist Styles Stronger Than Reflector and Activist Style, the Latter Being the Weakest (Kolb, 2013)

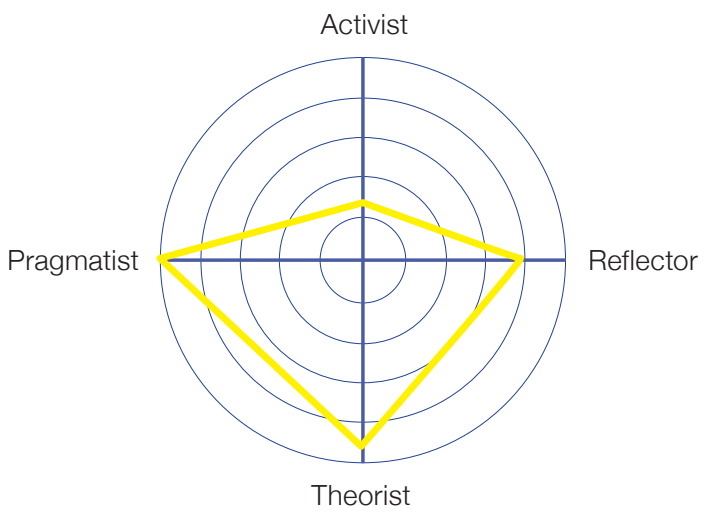




\section{Learning approach inventory}

The Revised Two Factor Study Process Questionnaire (R-SPQ-2F) was used to inventory participants' learning approaches (Biggs et al., 2001). This questionnaire consists of two major scales (i.e., motive and strategy) and two further subscales (i.e., deep and surface) for the learning approach. By combining the major scales and subscales, one of four variants is indicated for respondents: deep motive and deep strategy (DMDS), deep motive and surface strategy (DMSS), surface motive and deep strategy (SMDS) and surface motive and surface strategy (SMSS). All four subscales of this tool were validated with an acceptable Cronbach's alpha value of $0.62,0.72,0.63$ and 0.57 , respectively (Biggs et al., 2001). The authors also found a comparative fitness index of 0.997 for deep motive and 0.998 for the other three subscales (Biggs et al., 2001). The R-SPQ-2F comprises 20 statements that investigate how individuals describe their attitudes towards learning, planning and processing new information. The electronic copy of the completed questionnaires, together with the scorecards, were sent to one of the researchers (AAKW), who checked for correctness of scoring.

\section{Statistical analyses}

Data were collated and entered into Microsoft Excel (Version 16.0) and, later, transferred to SPSS Version 25 for further analysis. The relationship between academic performance and learning characteristics was investigated using a whisker box plot, which displays the median and interquartile ranges for each of the three learning characteristics groups. Pearson's correlation was performed to investigate the relationship between academic performance and the different learning modes (VARK), learning approaches (DMDS, DMSS, SMDS, SMSS) and learning styles (activist, theorist, pragmatist, reflector). Spearman's rho correlation was performed to analyse the association between the three learning characteristics. In both correlations, the coefficient $(r)$ ranges from -1 to +1 . More than zero to 1 indicates a positive relationship. Correlations were significant at the $p$-value $\leq 0.05$ (two-tailed testing) (Streiner et al., 2015).

\section{Results}

Of the 250-student population sampled, 180 agreed to participate in the study (response rate $=72 \%)$. Male students made up $21 \%(\mathrm{n}=38)$, while female students constituted $79 \%(\mathrm{n}=142)$. The pass rate among participants of this study was $72 \%$; the department's standard pass mark of $50 \%$ was used. The mean mark obtained by the participants was $55.1 \% \pm 11.1$ (maximum mark $=78$; minimum mark $=23$ ). Twenty-five participants $(14 \%)$ scored $\geq 70 \%$ [high achievers]; $21 \%(\mathrm{n}=38)$ scored between $60 \%$ and $69 \%$ [substantial achievers]; 37\% $(\mathrm{n}=67)$ scored between 50\% and 59\% [adequate achievers]; $19 \%(\mathrm{n}=34)$ scored between $40 \%$ and $49 \%$ [moderate achievers]; while low achievers, i.e., those who scored below 39\%, made up $9 \%(\mathrm{n}=16)$ of the respondents. 


\section{Learning modes and academic performance}

Our findings reveal that most $(35 \% ; n=63)$ participants were visual learners. The multimodal group achieved the highest mean mark $(60.7 \pm 10.5)$, while the auditory group achieved the lowest mean mark $(49.2 \pm 10.7)$ in the test. There was a statistically significant difference between the marks obtained by groups, determined by one-way ANOVA $(F(4,175)=7.718, p=0.0001)$. A Tukey post hoc test revealed that marks obtained by the participants who were multimodal $(60.7 \pm 10.5)$ were statistically significantly higher than marks of those who were auditory (49.2 \pm 10.7$)$, read and write $(52.9 \pm 9.8)$ and kinaesthetic $(49.6 \pm 14.2)$, with $p=0.0001,0.024$ and 0.0001 , respectively.

Further analysis of academic performance across learning modes found that multimodal learners had the highest median mark $(63 \%$; interquartile range $(I Q R)=21)$ compared to auditory $(50 \%$; IQR $=13)$, kinaesthetic $(51 \% ; \mathrm{IQR}=19)$, read and write $(52 \% ; \mathrm{IQR}=12)$ and visual $(58 \%$; IQR $=10)$ learners, thus, suggesting that multimodal learners performed better in the test.

\section{Learning styles and academic performance}

The majority $(25 \% ; n=45)$ of the participants were pragmatists with an average mark of $55.8 \pm 11.9$. Analysis by one-way ANOVA showed a statistically significant difference between marks obtained by the different learning style groups $(F(4)=9.077, p=0.0001)$. Learners with a balanced learning style made up $23.3 \%(\mathrm{n}=42)$ of the respondents and had the highest marks in the test $(61.3 \pm 7.5)$ — statistically significantly higher than marks obtained by learners with activist $(45.2 \pm 12.7, p=0.0001)$ and theorist $(53.4 \pm 8.1$, $p=0.005)$ learning styles.

Further analysis of academic performance across learning style groups revealed that learners with balanced learning styles had the highest median mark $(62 \%$; IQR $=9)$ compared to learners with other learning styles. These findings suggest that while most students were pragmatists, the participants who had adopted the balanced learning style performed better in the test.

\section{Learning approach and academic performance}

Our findings reveal that the majority $(44 \% ; n=79)$ of the participants utilised the SMSS approach in their learning. Only $26 \%(n=46)$ of the participants indicated that they used DMDS. One-way ANOVA revealed that there was a statistically significant difference between marks obtained by the DMDS group versus DMSS or SMDS or SMSS groups (i.e., $63.9 \pm 7.7$ versus $56.1 \pm 8.2$ or $53.9 \pm 12.3$ or $50.1 \pm 10.1 ; p=0.004$, 0.0001 and 0.0001 , respectively).

Further analysis of academic performance across learning approach groups shows that the DMDS group had the highest median mark (64\%) compared to $54 \%, 52 \%$ and $51 \%$ of the DMSS, SMDS and SMSS groups, respectively. We also found that, except for four 
students (outliers), all learners who used the DMDS approach to learn passed the test (i.e., scored $\geq 50 \%$ ). These findings suggest that students who adopted a DMDS approach to learning performed better in the test than students who adopted DMSS or SMDS or SMSS to learn.

\section{Strength of association between academic performance and learning characteristics}

Having shown that there was a possible association between students' performance (\% marks) in their first chemical pathology test and the various learning characteristics, we set out to investigate the strength of the associations using Pearson's correlations coefficients $(r)$. Findings reported in Table 1 show a low positive correlation between students' performance and multimodal learning mode $\left(r=0.262^{* *} ; p=0.0001\right)$, a moderate positive correlation between students' performance and balanced learning style $\left(r=0.307^{* *} ; p=0.0001\right)$ and a high positive correlation between students' performance and DMDS learning $\left(r=0.467^{* *} ; p=0.0001\right)$. A very poor positive correlation was also found with the visual learning mode $\left(r=0.15^{*} ; p=0.049\right)$ and a high negative correlation between academic performance and SMSS $\left(r=-0.406^{* *} ; p=0.0001\right)$.

\section{Table 1}

Pearson's Correlation Between Academic Performance (Marks \%) and Each Learning Characteristic $(\mathrm{n}=180)$

\begin{tabular}{|c|c|c|c|c|c|c|c|}
\hline \multicolumn{2}{|c|}{ Pearson's Correlation } & Marks \% & Visual & Auditory & $\begin{array}{l}\text { Read and } \\
\text { write }\end{array}$ & Kinaesthetic & Multimodal \\
\hline \multirow{8}{*}{$\begin{array}{c}\text { Marks } \\
\%\end{array}$} & $\begin{array}{l}\text { Pearson's } \\
\text { correlation }\end{array}$ & 1 & $0.147^{*}$ & $-0.210^{* *}$ & -0.086 & $-0.210^{* *}$ & $0.262^{* *}$ \\
\hline & Sig. (2-tailed) & & 0.049 & 0.005 & 0.251 & 0.005 & 0.000 \\
\hline & & Marks \% & Activist & Theorist & Reflector & Pragmatist & Balanced \\
\hline & $\begin{array}{l}\text { Pearson's } \\
\text { correlation }\end{array}$ & 1 & $-0.325^{* *}$ & -0.082 & -0.015 & 0.035 & $0.307^{* *}$ \\
\hline & Sig. (2-tailed) & & 0.000 & 0.271 & 0.837 & 0.645 & 0.000 \\
\hline & & Marks $\%$ & DMDS & DMSS & SMDS & SMSS & \\
\hline & $\begin{array}{l}\text { Pearson's } \\
\text { correlation }\end{array}$ & 1 & $0.467^{* *}$ & 0.039 & -0.047 & $-0.406^{* *}$ & \\
\hline & Sig. (2-tailed) & & 0.000 & 0.602 & 0.529 & 0.000 & \\
\hline
\end{tabular}

* Correlation is significant at the 0.05 level (2-tailed)

** Correlation is significant at the 0.01 level (2-tailed)

\section{Strength of association between the various learning characteristics}

The Spearman correlation coefficient was used to investigate the strength of the association between the various learning characteristics. Our data shows a low but significant positive correlation between multimodal learning mode and DMDS approach 
to learning $\left(r=0.227^{* *} ; p=0.002\right)$ and a significant negative correlation between the multimodal mode and the SMSS approach to learning $(r=-0.265 ; p=0.0001)$. A significant positive correlation was found between the balanced learning style and the DMDS learning approach $\left(r=0.429^{* *} ; p=.0001\right)$. Notably, a positive correlation was found between activist learning style and SMSS learning approach $\left(r=0.237^{* *} ; p=\right.$ $0.001)$. A significant positive relationship between the balanced learning style and visual learning mode $\left(r=0.282^{* *} ; p=0.0001\right)$ was also recorded, while pragmatist style was found to positively correlate with the multimodal learning mode $\left(r=0.267^{* *} ; p=0.0001\right)$.

\section{Discussion}

The findings of this study show that the majority of students were unimodal learners with a preference for the visual learning mode, which corroborates findings reported in the literature (O'Mahony et al., 2016; Shenwai \& Patil, 2017; Soundariya et al., 2017). Women were more likely to be visual than men (Soundariya et al., 2017). It is, therefore, possible that the high percentage of visual learners recorded by this study can be attributed to the large number of female participants. The use of multiple learning modes has been reported to be beneficial for students when learning highly conceptual subjects (Stocking, 2010). Analysis of this study's findings reveals that multimodal learners performed better in the test compared to students using other learning modes. These findings are consistent with similar findings by Nuzhat et al. (2013) and Alkhasawneh et al. (2008). Multimodal learners are characteristically able to match their preferences with whatever mode(s) of teaching being used, thus, making them effective learners (Alkhasawneh et al., 2008). This was evident in our findings, where multimodal learning mode correlated significantly with students' marks $(r=0.262 ; p \leq 0.0001)$. Furthermore, our study showed that multimodal learning correlated positively with a DMDS learning approach $(r=0.22 ; p \leq 0.002)$ and negatively with a SMSS approach $(r=-0.265 ; p \leq$ $0.0001)$. This suggests that students will benefit more if teaching methods include a blend of activities that stimulate all four sensory modalities, while also catering to the specific needs of unimodal learners.

An individual's learning style is a description of attitudes and behaviours that determine the preferred way of learning, and it describes the unique way an individual spirals through the learning cycle (Honey \& Mumford, 1992). Learning style is not a fixed psychological trait but a dynamic state that results from interactions between the person and the learning environment, and it can be influenced by genetic makeup, particular life experiences, as well as the demands of the present learning environment (A. Kolb, 2013). Analysis of the learning styles inventory showed that the majority of the study participants were pragmatists, followed by balanced, theorist, reflector and activist learners. A balanced learning style is characterised by the ability to balance concrete experience, abstract conceptualisation, active experimentation and reflective observation, which may lead to good academic performance (D. Kolb, 2007). Similarly, our findings are that a balanced learning style correlates with students' marks significantly and 
positively (Table 1) and that students who adopt this style perform better in the test than those with other learning styles. Furthermore, our findings show that a balanced learning style significantly and positively correlates with a DMDS approach $(r=0.429 ; p \leq$ 0.0001), which suggests that students who adopt this learning style have a deep approach to learning and tend to understand the study material. Based on the abovementioned findings, it can be concluded that the ability of the balanced learner to study with a deep approach, balance concrete experiences, conceptualise, experiment and reflect account for their better performance in the test. We, therefore, propose that educators steer their learners towards adopting a balanced learning style by organising their educational activities in such a manner that it develops all four learning styles equally—activist (acting), pragmatist (experiencing), reflector (reflecting) and theorist (thinking). Teaching modalities should facilitate the transition from one learning style to the other. The new knowledge created when a concrete experience is enriched by reflection, given meaning by thinking and transformed by action is often richer, broader, deeper and better (D. Kolb, 2007).

According to Mirghani et al. (2014), a "learning approach is the characteristic cognitive, affective and psychosocial behaviours that serve as indicators of how learners perceive, interact with and respond to the learning environment" (p. 10). Three different learning approaches are reported in the literature, namely, deep approach (DA), surface apathetic approach (SAA) and strategic approach (SA) (Leite et al., 2010). A deep approach to learning is described as an organised method of learning that emphasises understanding concepts and relating ideas, and it is considered the preferred approach to learning at university level and among medical students in the clinical years of training (Leite et al., 2010; Mirghani et al., 2014; Samarakoon et al., 2013). Similarly, physicians who have a deep approach to learning are more likely to be lifelong learners than those who adopt a surface approach (Newble et al., 1990). Findings of this present study indicate that participants who adopted a deep approach to learning chemical pathology performed better (mean mark $63.9 \pm 7.7$ ) than those who employed a surface approach (mean mark $50.1 \pm 10.1)$ and that the majority of those who failed the test had adopted a superficial motive and superficial strategy to learning. Using videos and simulation for teaching, analogy, construct mechanisms and concept maps, an appropriate range of learning resources, self-reflection and peer-tutoring; developing critical thinking skills; asking for and providing feedback; applying knowledge learned to new problems; learning by doing and service learning; and learning from patients are some of the practical, day-to-day learning/teaching activities that teachers can apply to enable deep learning (Azer et al., 2013; Mitra et al., 2010).

Overall, the present study provides a snapshot of the association that exists between student learning characteristics and academic performance in chemical pathology at a medical university in South Africa. 


\section{Limitations}

Our study faced several limitations. Firstly, it was only a cross-sectional study, with a small sample size, as it was restricted to fourth-year medical students at a single institution. Secondly, the results of this study cannot be generalised, as they might be specific to the participants and learning environment described in the study. Collaborative research with other medical colleges with similar or different curricula could be helpful in planning or revising teaching strategies and assessment methods. Thirdly, using a single test score in chemical pathology, rather than a cumulative score, may not depict the academic strength of an individual in the subject. Nonetheless, the knowledge of the relationship between students' learning characteristics and academic performance will help formulate strategies to enhance teaching and learning in this subject at the medical university involved, or any medical college with a similar context.

\section{Conclusion}

In conclusion, our findings reveal that a multimodal learning mode, balanced learning style and deep learning approach (DMSS) are associated with higher academic performance in chemical pathology. This concurs with findings by similar studies that report a positive association between these learning characteristics and academic performance in other subjects in undergraduate medicine (Bokhari \& Zafar, 2019; Cimermanová, 2018; Lujan \& DiCarlo, 2006). Based on these findings, we propose that chemical pathology educators explore alternative teaching and learning activities described in this study to move students towards these positive learning characteristics to achieve effective learning. Teaching and assessment practices should include training and examining abilities to conceptualise the subject, apt application of the learned concept in different clinical contexts and reflection on practices so that learning is aligned to assessment and vice versa.

\section{Acknowledgment}

The authors wish to thank all the fourth-year medical students of 2020 at the institution who participated in this study.

\section{Conflicts of interest and funding}

The Health and Welfare Sector Education and Training Authority (HWSETA), South Africa, funded this study. All authors declare that there are no conflicts of interest.

\section{References}

Alkhasawneh, I. M., Mrayyan, M. T., Docherty, C., Alashram, S., \& Yousef, H. Y. (2008). Problem-based learning (PBL): Assessing students' learning preferences using VARK. Nurse Education Today, 28(5), 572-579. https://doi.org/10.1016/j. nedt.2007.09.012 
Azer, S. A., Guerrero, A. P., \& Walsh, A. (2013). Enhancing learning approaches: Practical tips for students and teachers. Medical Teacher, 35(6), 433-443. https://doi. org/10.3109/0142159X.2013.775413

Biggs, J. (2012). What the student does: Teaching for enhanced learning. Higher Education Research \& Development, 31(1), 39-55. https://doi.org/10.1080/07294360.2 $\underline{012.642839}$

Biggs, J., Kember, D., \& Leung, D. Y. (2001). The revised two-factor study process questionnaire: R-SPQ-2F. British Journal of Educational Psychology, 71(1), 133-149. https://doi.org/10.1348/000709901158433

Bokhari, N. M., \& Zafar, M. (2019). Learning styles and approaches among medical education participants. Journal of Education and Health Promotion, 8, 181. https:// www.ncbi.nlm.nih.gov/pmc/articles/PMC6796290/

Cimermanová, I. (2018). The effect of learning styles on academic achievement in different forms of teaching. International Journal of Instruction, 11(3), 219-232. https://doi.org/10.12973/iji.2018.11316a

Cockerton, T., Naz, R., \& Sheppard, S. (2002). Factorial validity and internal reliability of Honey and Mumford's Learning styles questionnaire. Psychological Reports, 91(2), 503-519. https://doi.org/10.2466\%2Fpr0.2002.91.2.503

Honey, P., \& Mumford, A. (1982). Manual of learning styles. Peter Honey.

Honey, P., \& Mumford, A. (1992). The manual of learning styles (3rd ed.). Peter Honey.

Khromova, V., \& Gray, T. A. (2008). Learning needs in clinical biochemistry for doctors in foundation years. Annals of Clinical Biochemistry, 45(1), 33-38. https://doi. org/10.1258\%2Facb.2007.007122

Kolb, A. Y. (2013). The Kolb Learning Style Inventory 4.0: A comprehensive guide to the theory, psychometrics, research on validity and educational applications. Hay Group.

Kolb, D. A. (2007). The Kolb Learning Style Inventory. Hay Resources Direct.

Kolb, D. A. (2014). Experiential learning: Experience as the source of learning and development. Pearson FT Press.

Kolb, D. A., \& Fry, R. E. (1974). Toward an applied theory of experiential learning. MIT Alfred P. Sloan School of Management. 
Lau, N. K. C., Lau, K. N., \& Mak, C. M. (2018). Survey on chemical pathology teaching in medical curricula: Insight into patient safety. Biomedical Journal of Scientific \& Technical Research, 2(3), 1-9. https://doi.org/10.26717/BJSTR.2018.02.000753

Leite, W. L., Svinicki, M., \& Shi, Y. (2010). Attempted validation of the scores of the VARK: Learning styles inventory with multitrait-multimethod confirmatory factor analysis models. Educational and Psychological Measurement, 70(2), 323-339. https:// doi.org/10.1177\%2F0013164409344507

Lujan, H. L., \& DiCarlo, S. E. (2006). First-year medical students prefer multiple learning styles. Advances in Physiology Education, 30(1), 13-16. https://doi. org/10.1152/advan.00045.2005

Mirghani, H. M., Ezimokhai, M., Shaban, S., \& van Berkel, H. J. (2014). Superficial and deep learning approaches among medical students in an interdisciplinary integrated curriculum. Education for Health, 27(1), 10-14. https://doi.org/10.4103/1357$\underline{6283.134293}$

Mitra, B., Lewin-Jones, J., Barrett, H., \& Williamson, S. (2010). The use of video to enable deep learning. Research in Post-Compulsory Education, 15(4), 405-414. https:// doi.org/10.1080/13596748.2010.526802

Newble, D., Hejka, E., \& Whelan, G. (1990). The approaches to learning of specialist physicians. Medical Education, 24(2), 101-109. https://doi. org/10.1111/j.1365-2923.1990.tb02507.x

Nuzhat, A., Salem, R. O., Hamdan, N. A., \& Ashour, N. (2013). Gender differences in learning styles and academic performance of medical students in Saudi Arabia. Medical Teacher, 35(Suppl. 1), S78-S82. https://doi.org/10.3109/014215 9X.2013.765545

O’Mahony, S. M., Sbayeh, A., Horgan, M., O’Flynn, S., \& O’Tuathaigh, C. M. (2016). Association between learning style preferences and anatomy assessment outcomes in graduate-entry and undergraduate medical students. Anatomical Sciences Education, 9(4), 391-399. https://doi.org/10.1002/ase.1600

Samarakoon, L., Fernando, T., Rodrigo, C., \& Rajapakse, S. (2013). Learning styles and approaches to learning among medical undergraduates and postgraduates. $B M C$ Medical Education, 13(1), 1-6. https://doi.org/10.1186/1472-6920-13-42 
Shenwai, M. R., \& Patil, K. B. (2017). Assessment of learning style preferences and their influence on gender $\&$ academic performance among first year medical undergraduate students. National Journal of Integrated Research in Medicine, 8(1), 109-115. http://nicpd.ac.in/ojs-/index.php/njirm/article/view/1181

Soundariya, K., Deepika, V., \& Kalaiselvan, G. (2017). A study on the learning styles and learning approaches among medical students. National Journal of Physiology, Pharmacy and Pharmacology, 7(9), 1020-1025. https://doi.org/10.5455/ njppp.2017.7.0413011052017

Stanfliet, J., Macauley, J., \& Pillay, T. (2009). Quality of teaching in chemical pathology: Ability of interns to order and interpret laboratory tests. Journal of Clinical Pathology, 62(7), 664-666. https://doi.org/10.1136/jcp.2009.064824

Stocking, N. (2010). Conceptual understanding and retention of vocabulary for visual learners. Fisher Digital. https://fisherpub.sjfc.edu/cgi/viewcontent. cgi? article $=1103 \&$ context $=$ education_ETD_masters

Streiner, D. L., Norman, G. R., \& Cairney, J. (2015). Health measurement scales: A practical guide to their development and use. Oxford University Press, USA.

Urban, S. (2004). The Teaching-Learning Style-Wheel of Honey and Mumford (1995). https://sites.ualberta.ca/-urban/Learning/TL\%20Style\%20Wheel.pdf

VARK Learning Limited. (2020). The VARK questionnaire: VARK Questionnaire 7.8. Retrieved April, 20 2020, from https://vark-learn.com/the-vark-questionnaire/ 